\title{
OS PAPÉIS SOCIAIS DA ESCOLA PÚBLICA EM TEMPOS DE PANDEMIA
}

\author{
THE SOCIAL ROLES OF PUBLIC SCHOOL IN TIMES OF PANDEMIC \\ LAS FUNCIONES SOCIALES DE LA ESCUELA PÚBLICA EN TIEMPOS DE PANDEMIA
}

Walace Rodrigues ${ }^{1}$

\begin{abstract}
RESUMO
O presente texto busca pensar sobre os papéis sociais das escolas públicas brasileiras em nossa sociedade atual, principalmente aquelas nas localidades mais vulneráveis das cidades e das zonas rurais, em época de pandemia, como a que atravessamos agora. Nosso trabalho aqui coloca-se como um ensaio, pois buscamos trabalhar com fontes que nos ajudassem a, qualitativamente, pensar sobre alguns dos mais importantes papéis das instituições escolares brasileiras. Nossos resultados mostram a relevância social da escola pública em áreas onde elas são, muitas vezes, a única instituição a representar a presença do Estado.
\end{abstract}

PALAVRAS-CHAVE: Escola pública brasileira. Sociedade. Papéis sociais.

\begin{abstract}
This paper seeks to think about the social roles of Brazilian public schools in our current society, especially those in the most vulnerable locations in the cities and those in rural areas, in times of pandemic, as we are currently going through. This work is an essay, because we seek to work with sources that would help us to, qualitatively, think about some of the most important roles of Brazilian school institutions. Our results show the social relevance of public schools in areas where they are often the only institution to represent the presence of the Government.
\end{abstract}

KEYWORDS: Brazilian public school. Society. Social roles.

RESUMEN: Este texto busca pensar en las funciones sociales de las escuelas públicas brasileñas en nuestra sociedad actual, especialmente las localidades de las ciudades y zonas rurales más vulnerables, en tiempos de pandemia, como estamos atravesando actualmente. Nuestro trabajo aquí es un ensayo, porque buscamos trabajar con fuentes que nos ayuden, cualitativamente, a pensar en algunos de los roles más importantes de las instituciones escolares brasileñas. Nuestros resultados muestran la relevancia social de las escuelas públicas en áreas donde a menudo son la única institución que representa la presencia del Estado.

PALABRAS CLAVE: Escuela pública brasileña. Sociedad. Funciones sociales.

\footnotetext{
1 Doutor em Humanidades, mestre em Estudos Latino-Americanos e Ameríndios e mestre em História da Arte Moderna e Contemporânea pela Universiteit Leiden (Países Baixos). Pós-graduado (lato sensu) em Educação Infantil pelo Centro Universitário Barão de Mauá - SP. Licenciado pleno em Educação Artística pela UERJ, com complementação pedagógica em Letras/Português e Pedagogia. Professor Adjunto da Universidade Federal do Tocantins (UFT). E-mail: walace@uft.edu.br
}

Revista de Ciências Humanas, Frederico Westphalen - RS, , v. 21, n.1, p. 98-111, jan./abr. 2020.

\begin{tabular}{l|l} 
Recebido em: $27 / 10 / 2020$ & Aceito em: 08/02/2021
\end{tabular}


A educação é o ponto em que decidimos se amamos o mundo o bastante para assumirmos a responsabilidade por ele.

Hannah Arendt

\section{INTRODUÇÃO}

O texto aqui apresentado parte de uma palestra online ofertada na Universidade Federal do Tocantins - UFT, campus de Araguaína, intitulada "Os papéis sociais da escola em tempos de pandemia de coronavírus" dentro do Simpósio Temático do Curso de Letras/UFT/Araguaína, em maio de 2020.

Tal Simpósio aconteceu devido à suspensão das aulas presenciais em nossa instituição universitária, pois muitos de nossos estudantes, tais como quilombolas, indígenas e aqueles em vulnerabilidade social, não poderiam acompanhar aulas online. Daí pensarmos em um Simpósio com palestras que pudessem chegar aos nossos estudantes via seus telefones celulares e que contasse como horas de atividades para eles.

Aqui buscamos mostrar um pouco sobre a história da educação brasileira e as desigualdades existentes já em sua base de formação. A partir daí, discutimos alguns dos mais relevantes papéis sociais da escola pública na sociedade atual, principalmente nesta época de pandemia de coronavírus, e terminaremos com algumas reflexões sobre o todo que expomos. Tentaremos, ainda, pensar em saídas possíveis para o período pós-pandemia de coronavírus.

Nossa análise parte de uma bibliografia nas áreas da educação, da história e da filosofia, e busca, qualitativamente, compreender como funcionam socialmente as escolas públicas brasileiras em suas localidades de atuação, principalmente nas áreas mais vulneráveis das cidades e do campo.

\section{DESIGUALDADES EDUCACIONAIS NO BRASIL E OS PAPÉIS DA ESCOLA PÚBLICA}

Nosso interesse por este tema partiu de uma reportagem jornalística intitulada "Três semanas sem merenda escolar em São Paulo: Já deixei de almoçar para alimentar meus filhos", do periódico online El País. Tal reportagem revelava o relato de uma mãe, numa periferia de São Paulo, que dependia da escola pública para a alimentação diária dos cinco filhos e que se via em apuros financeiros para comprar trabalhar por causa do isolamento social causado pela pandemia de coronavírus.

Revista de Ciências Humanas, Frederico Westphalen - RS, , v. 21, n.1, p. 98-111, jan./abr. 2020. Recebido em: 27/10/2020 Aceito em: 08/02/2021 
Esta reportagem levou-nos a pensar nas diferenças de ofertas de educação para as classes sociais mais abastadas e as mais vulneráveis no Brasil. Se as classes sociais com mais renda não dependem da escola para a merenda de seus filhos, as classes populares necessitam da merenda gratuita da escola pública para seus sustentos calóricos diários.

Vale ressaltar que entendemos vulnerabilidade como a confirmação de ameaças das mais distintas formas e as capacidades individuais e de diferentes grupos sociais de criarem ferramentas de superação para minimizar ou extinguir problemas.

Neste sentido, vemos que uma escola que alimenta seus alunos e profissionais colocase como humanizadora, não assistencialista, e combatedora de vulnerabilidade alimentar, pois: "A fome é incompatível com a civilização. É incompatível com a humanidade. É o naufrágio do homem" (RICO; LIRIA, 2010, p. 26, tradução nossa).

Vale ressaltar, também, que compreendemos as diferenças em estruturas, em dinâmicas, e nas relações profissionais e sociais de uma escola pública urbana e de uma escola pública rural. No entanto, queremos destacar o caráter humanizador da escola que deve ter suas necessidades supridas pelos governos municipais, estaduais e federais.

Tais observações acerca das diferenças e das vulnerabilidades revelam-nos a ponta do icebergue da história das desigualdades educacionais no Brasil. E isso desde sua fundação enquanto país colonizado, pois ainda temos uma sociedade com um alto grau de desigualdade social e escolas muito diferentes para atender a grupos sociais de níveis financeiros distintos. Vale a pena pensar em alguns momentos históricos que podem elucidar essas disparidades sociais e educacionais, como o que atravessamos agora, numa época de isolamento social por causa da epidemia do coronavírus. Jane Gizzi e Ricardo Mendonça afirmam que:

\begin{abstract}
A necessidade de confinamento como único meio eficaz de evitar o colapso no sistema de saúde e, com isso, propiciar a todos o recebimento de tratamento adequado, traz consigo questões das mais complexas, já que o isolamento social passa a ser um privilégio acessível apenas a uma parcela da população. Não se pode deixar de lembrar que milhões de brasileiros não têm moradia, e outros tantos não tem acesso à água potável, de modo que sua extrema vulnerabilidade os coloca no mais alto risco de sucumbir. (GIZZI; MENDONÇA, 2020, p. 231, negrito nosso).
\end{abstract}

Vemos, ainda, que a escola brasileira foi pensada, desde os seus primórdios, a partir dos modelos jesuíticos de ensino e concepção da sociedade a partir de uma visão tradicional de sociedade. Como precursores da educação nacional, estes religiosos dedicaram-se ao ensino em instituições que educavam os meninos das famílias mais abastadas.

Revista de Ciências Humanas, Frederico Westphalen - RS, , v. 21, n.1, p. 98-111, jan./abr. 2020. Recebido em: 27/10/2020 Aceito em: 08/02/2021 
Neste sentido, parece sempre ter existido uma escola para os mais ricos da sociedade brasileira, sendo os mais pobres relegados às migalhas educacionais. Na primeira metade do século XIX temos as seguintes situações educacionais no Brasil:

\begin{abstract}
A reforma da instrução primária realizada em 1837 na província do Rio de Janeiro, por exemplo, proibia a frequência à escola daqueles que sofressem de moléstias contagiosas, dos escravos e dos pretos africanos, ainda que livres e libertos. Some-se ainda, a essa realidade, o fato de que a população pobre e negra era maioria apenas nas escolas primárias, sendo que em níveis mais elevados do ensino aponta-se a predominância de pessoas brancas provenientes das elites da época (ALMEIDA; SANCHEZ, 2016, p. 236-237, negrito nosso).
\end{abstract}

A exclusão de grande parte da população das escolas primárias no século XIX era uma clara demonstração de uma sociedade pensada para beneficiar alguns em detrimento de outros. Ainda, este ensino voltado para os mais abastados e brancos revelou-se uma constante no Brasil.

Os mais variados movimentos em prol da educação nacional pública (movimento do Entusiamo Pela Educação, Escolanovista, Otimismo Pedagógico, etc) apareceram com força na primeira metade do século $X X$, mas não surtiram muito efeito na democratização do ensino público e gratuito. Os mais socialmente vulneráveis continuavam excluídos do sistema educacional governamental.

Um exemplo claro da educação para fins políticos foi a tentativa de alfabetização da população a partir da década de 1920. Valéria da Hora Bessa diz-nos que na década de 1920 $75 \%$ da população brasileira era analfabeta, assim: "como os analfabetos não podiam votar, surgiram, nessa época, várias alianças contra o analfabetismo, pois o voto seria a única maneira de retirar do poder a permanência do favorecimento às sociedades cafeeiras" (BESSA, 2008, p. 18).

Benerval Santos revela-nos que, historicamente, a escola brasileira "cumpriu um papel de triagem social e não o de constituir-se como um espaço/instituição para a construção de cidadãos afinados com seus anseios, desejos e problemas relacionados às necessidades sociais" (SANTOS, 2011, p. 313). E Paulo Freire corrobora com esta ideia, afirmando que as instituições educacionais são entidades marcadas por uma historicidade de dominação:

Os lares e as escolas, primárias, médias e universitárias, que não existem no ar, mas no tempo e no espaço, não podem escapar às influências das condições objetivas estruturais. Funcionam, em grande medida, nas estruturas dominadoras, como agências formadoras de futuros 'invasores'. (FREIRE, 2013,

Revista de Ciências Humanas, Frederico Westphalen - RS, , v. 21, n.1, p. 98-111, jan./abr. 2020. Recebido em: 27/10/2020 Aceito em: 08/02/2021 
Na mesma linha de pensamento, Walace Rodrigues (2019) informa-nos sobre a possibilidade da educação pública ofertada aos mais vulneráveis ser um caminho possível de melhora de vida no futuro destas pessoas:

[...] a educação pode funcionar como um mecanismo de abertura de oportunidades sociais para os estudantes menos favorecidos sócio e financeiramente, vemos que a vulnerabilidade educacional que atinge as crianças em fase escolar infantil pode levar a mais desigualdade social do que já temos hoje. Além de aumentar o gap educacional entre ricos e pobres de nosso país. (RODRIGUES, 2019, p. 81).

Já na atualidade, o filósofo e educador Edgar Morin (2020) fala-nos que a pandemia de coronavírus trouxe-nos várias incertezas. Ele instala a incerteza em todas as áreas sociais póspandemia, também na área educacional:

\begin{abstract}
O que é muito interessante, na crise do coronavírus, é que ainda não temos certeza sobre a própria origem desse vírus, nem sobre suas diferentes formas, as populações que ataca, seus graus de nocividade. Mas também estamos passando por uma grande incerteza sobre todas as consequências da epidemia em todas as áreas, sociais, econômicas, etc... (...) A chegada do coronavírus nos lembra que a incerteza permanece um elemento inexpugnável da condição humana. Todo o seguro social em que você pode se inscrever nunca poderá garantir que você não ficará doente ou será feliz em sua casa. (MORIN, 2020, s/p, negrito nosso).
\end{abstract}

Confirmando os pensamentos de Morin na citação anterior, Lucilene Cury, trabalhando com alguns conceitos deste filósofo, comenta-nos que a incerteza auxilia-nos a percebermos nossas fragilidades, principalmente num momento de pandemia como este que atravessamos agora, levando-nos a agir de forma mais ética e com mais empatia para com os outros. Ela revela que Morin:

\footnotetext{
Trata da incerteza como condição natural do pensamento e da produção humana. Fator gerador do avanço das ciências e do entendimento da espécie e do planeta, a incerteza presente em tudo que foi criado pelo homem enfatiza a necessidade de consciência e de compreensão da nossa condição de seres humanos, bem como da consciência ética e da sociedade. No seu pensamento integrado, ele não separa 0 ser humano, que denomina sujeito responsável de suas atitudes em relação a si mesmo, do mundo e das coisas. Por isso, também a ética faz parte do ser e do agir na sociedade. Nesse sentido, as finalidades não são impostas como nas sociedades individualistas. (CURY, 2012, p. 44-45, negrito nosso).
}

Vale ressaltar aqui que quando falamos de ética estamos nos referindo ao modo de

Revista de Ciências Humanas, Frederico Westphalen - RS, , v. 21, n.1, p. 98-111, jan./abr. 2020. Recebido em: 27/10/2020 Aceito em: 08/02/2021 
viver através do pensamento humano, do pensamento crítico. A ética tem como objetivo fazer com que as pessoas reflitam sobre suas ações. Isso faz com que elas coloquem a razão acima das suas paixões, buscando alcançar a felicidade individual e coletiva, já que o ser humano é um ser social e vive em sociedade. Assim, atitudes éticas devem ter em vista o bem comum.

Pensando de forma aristotélica, a racionalidade prática deve visar a um fim ou a um bem e a ética tem como objetivo buscar a finalidade suprema (aqui a felicidade não é aquela das riquezas, honrarias e prazeres) que justifica todas as outras. Isso também nos leva a pensar sobre quais maneiras de alcançar tal objetivo.

Sabemos que a atual situação de teletrabalho de muitos professores chega a ser estafante, já que a grande maioria deles não foi preparada para trabalhar com a modalidade de ensino a distância. Além disto, a falta de acesso à internet para os estudantes mais vulneráveis dificulta o processo de aprendizado destes estudantes, como nos informam Juina Zaidan e Ana Carolina Galvão:

\begin{abstract}
Na esfera educacional, com a suspensão das aulas imposta pela pandemia, proliferou-se a adoção de atividades e modalidades de ensino a distância, em rede, online, remotas, EaD e outras designações, tanto na educação pública quanto privada, ainda que não em sua totalidade. Para esta breve discussão, interessa-nos, especificamente, ressaltar o aprofundamento da exploração da força de trabalho docente por meio do teletrabalho, sem considerar a questão em si da inadequação das formas de EaD para uma educação emancipatória, que necessariamente inscreve um projeto de sociedade. Tampouco estamos endereçando a qualidade dos conteúdos e da proposta didática das plataformas adotadas ou mesmo a questão decerto candente a esse respeito, que é a exclusão que as atividades a distância promovem daqueles estudantes que não usufruem de estrutura - conexão, equipamento e outras condições que nos afetam subjetiva e objetivamente - para manter a rotina de estudos durante o isolamento social. Uma análise conjuntural da educação face a pandemia deverá levar em conta estes e muitos outros aspectos, mas atemo-nos aqui a superexploração do trabalho docente. (ZAIDAN; GALVÃO, 2020, p. 264, negrito nosso).
\end{abstract}

E em relação à escola? Como voltaremos a trabalhar após o isolamento social imposto? Como se nada tivesse acontecido? Como trabalharemos quando retornarmos às salas de aula? Muitas são as questões a serem respondidas e poucas são as certezas.

Neste caminho, vale pensar sobre os papéis sociais da escola pública brasileira, escola esta fundada na desigualdade de acesso de ontem e que continua na desigualdade de qualidade de hoje.

Vale dizer que quando falamos em qualidade em educação pública estamos englobando uma série de condições para o bom funcionamento da escola: remuneração 
adequada para os professores, merenda escolar de boa procedência e abundante para toda a comunidade escolar (estudantes, professores, técnicos, etc), estrutura física da escola adequada para as demandas de atividades, limpeza da escola, boa qualidade do material didático utilizado pelos alunos e à disposição dos professores, bibliotecas escolares bem equipadas e com um profissional com formação na área, equipamentos de tecnologia para o uso de alunos e professores, internet rápida, entre tantos outros pontos.

Sobre qualidade, a Lei de Diretrizes e Bases da Educação - Lei 9.394/96, determina que:

\begin{abstract}
Art. 400 dever do Estado com educação escolar pública será efetivado mediante a garantia de: (...)

VIII - atendimento ao educando, em todas as etapas da educação básica, por meio de programas suplementares de material didático-escolar, transporte, alimentação e assistência à saúde;

IX - padrões mínimos de qualidade de ensino, definidos como a variedade e quantidade mínimas, por aluno, de insumos indispensáveis ao desenvolvimento do processo de ensino-aprendizagem (BRASIL, 1996, Art. $4^{\circ}$, negrito nosso).
\end{abstract}

A nosso ver, a mercantilização do ensino e a neoliberalização das relações profissionais de docentes, diretores, merendeiras, e todos os outros profissionais que trabalham na educação, acabou por precarizar ainda mais a educação pública brasileira. Neste movimento de globalização, as escolas públicas foram engolidas pelo discurso neoliberal que somente aumenta as desigualdades sociais. Freire afirma-nos que:

\footnotetext{
O discurso da globalização que fala da ética esconde, porém, que a sua é a ética do mercado e não a ética universal do ser humano. (...) 0 discurso ideológico da globalização procura disfarçar que ela vem robustecendo a riqueza de uns poucos e verticalizando a pobreza e a miséria de milhões. (FREIRE, 1996, p. 144, negrito nosso).
}

Também vale lembrar que o capitalismo criou um homem voltado para o consumo, tornando tudo mercadoria, até mesmo a educação escolar. Nesta lógica, o capitalismo proletarizou tudo que temos e parece ter "quebrado" quando nos deparamos como uma ameaça universal como a da pandemia do coronavírus. As fábricas tiveram que parar, somente compramos o essencial em supermercados e farmácias, os meios de transporte público foram paralisados ou largamente diminuídos, entre outros acontecimentos. Roupas de grife e sapatos caros não importam neste momento de isolamento social, pois não temos para quem mostrá-los,

Revista de Ciências Humanas, Frederico Westphalen - RS, , v. 21, n.1, p. 98-111, jan./abr. 2020. Recebido em: 27/10/2020 Aceito em: 08/02/2021 
rompendo, pelo menos que momentaneamente, com a lógica consumista e exibicionista do capitalismo. Sobre esse capitalismo de hoje, Rico e Liria dizem que:

\begin{abstract}
A razão ilustrada prometeu cidadania universal: igualdade, liberdade, fraternidade. Mas é o capitalismo, e não a iluminação, que deixou o homem para trás para instalar os corpos em uma realidade pós-humana. Agora são os próprios seres humanos que correm atrás da História, com a língua para fora. $\mathrm{E}$ quando conseguem alcançá-lo, sua pele permanece apenas ou, pior ainda, sua imagem: ao longo do caminho deixaram seus ritos, deuses, ancestrais, laços tribais, densidades culturais, até sexo ou idade. Em vez disso, encontram a proletarização de empregos e prazeres e a ameaça de destruição planetária. (RICO; LIRIA, 2010, p. 26, tradução nossa, negrito nosso).
\end{abstract}

Após essa discussão histórica e humanista, começamos a descrever sobre os papéis sociais da escola pública brasileira. O primeiro papel social da escola pública que desejamos destacar é o de educar, mas não somente educar com conteúdos de disciplinas variadas, mas também educar 0 estudante a lidar com 0 outro num ambiente de polidez social. Muitos alunos estão desacostumados a dar um "bom dia", "boa tarde", um "por favor", um "obrigado", etc.

Além deste educar referentes a conteúdos e polidez social, a partir do retorno às aulas, na época pós-pandemia, a escola deverá reforçar a educação sanitária. Ensinar as crianças a lavar a mão regularmente na escola, usar álcool gel e talvez até utilizar máscaras de proteção facial.

Na mesma linha de pensamento, o segundo papel da escola seria o de socialização. As crianças chegam à escola para aprendem através da interação com os coleguinhas e profissionais da escola. Esse papel social também coloca como de fundamental importância a inclusão dos colegas ditos "diferentes". A aceitação do "outro" e do "diferente" passa a ser tido como cotidiano. As crianças devem aprender que muita riqueza nasce da compreensão das diferenças, pois somente nos vemos e nos conhecemos através da relação que fazemos com 0 outro.

O terceiro papel é o de criação. A escola como locus da criatividade e da inventividade. Uma escola que incentive o fazer inovador em todos os sentidos. Mas para isso é necessário ter professores com aguçado pensamento crítico e oferecendo aos seus estudantes atividades que os façam pensar "fora da caixinha". A arte-educadora Ana Mae Barbosa informa-nos que a criatividade é, muitas vezes, negada aos estudantes mais vulneráveis socialmente:

Sonegação de informação das elites para as classes populares é uma constante no Brasil, onde a maioria dos poderosos e até alguns educadores acham que

Revista de Ciências Humanas, Frederico Westphalen - RS, , v. 21, n.1, p. 98-111, jan./abr. 2020. Recebido em: 27/10/2020 Aceito em: 08/02/2021 
esta história de criatividade é para criança rica. Segundo eles, os pobres precisam somente aprender a ler, escrever e contar. 0 que eles não dizem, mas nós sabemos é que, assim, estes pobres serão mais facilmente manipulados. (BARBOSA, 1995, p. 64, negrito nosso).

O quarto papel social que desejamos destacar para a escola pública é de ser um local de respeito. Como já dissemos, de respeito ao diferente, de respeito aos professores, de respeito aos funcionários da escola, de respeito para com o pensamento divergente do outro, enfim, um lugar onde a civilidade social seja a tônica.

O quinto papel social da escola e que vemos como um dos mais importantes para os estudantes mais vulneráveis é ser um lugar de alimentação diária. É na escola que muitas crianças pobres têm sua única refeição nutritiva do dia. A escola passa a fornecer às crianças algo tão básico, mas que elas, muitas vezes, não têm em casa: comida. 0 Estatuto da Primeira Infância, Lei da 13.257, de 8 de março de 2016, reforça o direito das crianças, desde a creche, à saúde, alimentação e nutrição, conforme passagem a seguinte passagem:

\begin{abstract}
Constituem áreas prioritárias para as políticas públicas para a primeira infância a saúde, a alimentação e a nutrição, a educação infantil, a convivência familiar e comunitária, a assistência social à família da criança, a cultura, o brincar e 0 lazer, o espaço e o meio ambiente, bem como a proteção contra toda forma de violência e de pressão consumista, a prevenção de acidentes e a adoção de medidas que evitem a exposição precoce à comunicação mercadológica. (BRASIL, 2016, Art. 50).
\end{abstract}

O sexto e último papel da escola e que gostaríamos de enumerar aqui é como lugar de exercício da cidadania. O que queremos dizer com isso? É o lugar onde votamos nas eleições, onde há campanhas de vacinação para animais, onde se organiza a entrega de cestas básicas, enfim, onde a comunidade é atendida para além da educação.

Esse último papel da escola somente é exercido por ela por causa da confiança que as pessoas ainda têm nas instituições escolares públicas. Sem esta confiança a escola não seria um lugar de cidadania.

Ainda, em algumas localidades afastadas dos grandes centros ou em áreas vulneráveis, a escola pública é a única instituição que representa o Estado, sendo ela uma instituição governamental de verdade e prestando serviços necessários à população local.

Neste sentido, após a pandemia, teremos que pensar que não podemos ter uma escola de qualidade para formar os mais ricos e outra precarizada para formar os mais pobres, pois as desigualdades continuarão aguçadas em nosso país, já que:

Revista de Ciências Humanas, Frederico Westphalen - RS, , v. 21, n.1, p. 98-111, jan./abr. 2020. Recebido em: 27/10/2020 Aceito em: 08/02/2021 
O ambiente familiar exerce influência considerável sobre o desempenho escolar dos alunos, e aqueles da classe social baixa, ainda quando começaram 0 processo de escolarização na idade regular, apresentaram rendimento inferior relativamente aos demais colegas e, não raras vezes, são reprovados e repetem o ano, o que, quando não os leva a abandonar a escola, coloca-os numa posição de desvantagem relativamente a seus colegas que foram bem-sucedidos na carreira escolar. (COSTA apud SANTOS, 2011, p. 308).

Assim, devemos pensar em uma escola mais humanista pós-pandemia, uma escola com mais empatia, com mais acolhimento, mais solidária, de maior compreensão e valorização da vida e que acolha as várias dimensões dos seus estudantes.

Para Cury, a partir do pensamento de Morin, devemos construir novos conhecimentos e novas racionalidades para com a incerteza daquilo que, esperamos, tenhamos aprendido com a pandemia de coronavírus:

[...] o conhecimento deve trabalhar na incerteza e na dificuldade, com a intenção de chegar às chamadas novas racionalidades, para permitir uma caminhada aos novos tempos, quando a unicidade do saber deve dar lugar à pluralidade dos saberes em diálogo, e a fragmentação à unidade, temos que, como numa espécie de viagem, transitar pelo saber, atravessando as disciplinas para compor o todo capaz de ser utilizado por indivíduos em sua relação com 0 mundo global. (CURY, 2012, p. 46, negrito nosso).

Também, de acordo com o filósofo Edilson Santana, é necessário ao homem atual pensar em um humanismo com mais ética para com os outros e para com o planeta que nos carrega. Isto para que as coisas que criamos não se tornem ameças contra nós mesmos:

\begin{abstract}
No mundo contemporâneo, tudo se converte em ameaça e exige uma construção ética inédita, que tem como centro as tecnologias biológicas e a energia nuclear, para as quais os regramentos da tradição acham-se inoperantes. Neste contexto, torna-se inevitável o questionamento das éticas aplicadas, tais como a bioética. Tudo reclama um ethos mundial, uma ética universal, capaz de corrigir a rota que vem levando à grave crise da injustiça social. (SANTANA, 2007, p. 94 negrito nosso).
\end{abstract}

Dessa forma, a escola pós-pandemia deverá retomar com os alunos as questões da ética para com o próximo e para com o planeta. É inconcebível o nível de poluição atmosférica e plástica, por exemplo, que produzimos hoje em dia. O descaso para com o planeta revela-se assustador, como a destruição da floresta amazônia via incêndios criminosos, retirada ilegal de madeira e grilagem de terras, entre outras ameaças à natureza.

Revista de Ciências Humanas, Frederico Westphalen - RS, , v. 21, n.1, p. 98-111, jan./abr. 2020. Recebido em: 27/10/2020 Aceito em: 08/02/2021 
Como nos mostra Paulo Freire, é o homem que, com confiança dialógica e esperançosa de um futuro melhor, transforma o mundo em que vive: "É que a confiança, ainda que básica ao diálogo, não é um a priori deste, mas uma resultante do encontro em que os homens se tornam sujeitos da denúncia do mundo, para a sua transformação" (FREIRE, 2013, p. 230).

Vemos que ser crítico a partir de discussões sérias pós-pandemia e que afetam a todos nós humanos é premente e deve acontecer, também, a partir das escolas, sejam elas públicas ou privadas.

\section{ALGUMAS CONSIDERAÇÕES FINAIS}

Neste texto buscamos mostrar como a escola brasileira nasce com o estigma da desigualdade social. Tal estigma formalizou-se legalmente no século XIX com a Reforma da Instrução Primária de 1837 e deixou uma herança maldita até hoje. Mas isso não quer dizer que a educação escolar oferecida até este momento tenha sido menos desigual.

Vimos que a escola deve ser um espaço genuíno de promoção da tolerância em relação a todas as sortes de diferenças. Devendo ser um local de inclusão de todos os estudantes, auxiliando, assim, a aprenderem, através da riqueza dos contatos com o "outro", a ser mais tolerantes. Edgar Morin, no seu livro "Os sete saberes necessários à educação do futuro", falou-nos da necessidade de ensinar sobre a condição humana:

\footnotetext{
A educação do futuro deverá ser 0 ensino primeiro e universal, centrado na condição humana. [...] os seres humanos devem reconhecer-se em sua humanidade comum e, ao mesmo tempo, reconhecer a diversidade cultural inerente a tudo que é humano. Conhecer o humano é antes de tudo, situá-lo no universo, e não separá-lo dele. [...] Aqui se apresenta um problema epistemológico: é impossivel conceber a unidade complexa do ser humano pelo pensamento disjuntivo, que concebe nossa humanidade de maneira insular, fora do cosmos que o rodeia, da matéria física e do espírito somos constituídos, bem como pelo pensamento redutor, que restringe a unidade humana a um substrato puramente bioanatômico (MORIN, 2011, p. 43).
}

Ainda, a escola deve ter uma atuação social transformadora nas suas práticas, mas sempre sem esquecer-se das teorias educativas, principalmente numa época de pós-pandemia, como atravessaremos num futuro próximo.

Também num momento pós-pandemia, a escola deve levar a refletir sobre nossa condição humana e sobre nossa relação ética para com o planeta e para com os outros seres,

Revista de Ciências Humanas, Frederico Westphalen - RS, , v. 21, n.1, p. 98-111, jan./abr. 2020. Recebido em: 27/10/2020 Aceito em: 08/02/2021 
valorizando o ser humano sem pensar numa visão antropocentrista que vê a natureza como algo a ser subjugado.

Pensamos que as prefeituras, estados, governo federal e as próprias escolas deverão ter planos de retorno gradual, incluindo ações práticas, momentos reflexivos e explicativos para que os estudantes entendam pelo que estamos passando, preparando-os para um futuro ainda incerto. E neste retorno, teremos que pensar sobre as questões sanitárias, sobre outras doenças, sobre proteção individual e outros pontos mais relacionados às pandemias.

Em um país já tão afetado por enfermidades relacionadas à falta de saneamento básico, como zika, chikungunya e dengue, entre tantas outras, a pandemia de coronavírus representa um problema ainda mais grave de saúde pública.

Para além de toda degradação natural provocada pelo homem atual, a escola terá que ensinar, a todo momento, que o homem também é natureza, que ele também faz parte da natureza, não devendo, portanto, achar-se superior a ela, tentando subjugá-la a todo custo.

Neste sentido, vemos que a escola deverá tomar para si a tarefa de realmente explicar sobre a humanização para seus estudantes, pois teremos que nos libertar das formas "anteriores" de entendimento do mundo para conceber novas maneiras de lidar com tudo que nos cerca e nos afeta. Paulo Freire diz-nos que devemos lutar pela libertação de uma sociedade que nos oprime, revelando o melhor do homem:

\footnotetext{
Quem, melhor que os oprimidos, se encontrará preparado pra entender 0 significado terrivel de uma sociedade opressora? Quem sentirá, melhor que eles, os efeitos da opressão? Quem, mais que eles, para ir compreendendo a necessidade da libertação? Libertação a que não chegarão pelo acaso, mas pela práxis de sua busca pelo conhecimento e reconhecimento de lutar por ela. (FREIRE, 2013, p. 42-43).
}

Dessa forma, a escola pública, as vezes a única instituição do governo em áreas de alta vulnerabilidade social, seja nas cidades ou no campo, deverá compreender seu importante papel de dar direções planejadas para a "continuação" da vida pós-pandemia. Ou mesmo tentar caminhos de sobrevivência possíveis para cada comunidade estudantil e cada área onde a escola está localizada. Tratando da questão central deste texto, os seis papéis da escola pública levantados aqui, vemos que seriam eles, em grande medida, dirigidos a qualquer escola pública e não necessariamente às ditas mais vulneráveis, até mesmo a algumas escolas privadas. Tais papéis deveriam ser cumpridos independentemente de estarmos vivendo em um momento de pandemia, mas somente agravam-se e são mais percebidos durante este tempo de

Revista de Ciências Humanas, Frederico Westphalen - RS, , v. 21, n.1, p. 98-111, jan./abr. 2020. Recebido em: 27/10/2020 Aceito em: 08/02/2021 
crise de saúde coletiva. Vemos que tais papéis deveriam ser condições a priori de todas as escolas, mas, infelizmente, não o são.

Concluindo, vemos que as instituições escolares detêm um grande número de papéis sociais importantes para suas comunidades e que estes papéis talvez sejam ampliados num momento de pós-pandemia. Isto para dar apoio às comunidades onde estão instaladas e demonstrar acolhimento para com todos que dela dependem de alguma forma, revelando a importância ímpar de tal instituição social.

\section{Referências}

ALMEIDA, Marco Antonio Bettine de; SANCHEZ, Livia. Os negros na legislação educacional e educação formal no Brasil. Revista Eletrônica de Educação. V. 10, n. 2, 2016, pág. 234-246. Disponível em < http://dx.doi.org/10.14244/198271991459 >. Acesso em 11 mai. 2020.

BARBOSA, Ana Mae. Arte-Educação pós-colonialista no Brasil: aprendizagem triangular. Comunicação e Educação. Universidade de São Paulo, São Paulo, jan./abr. 1995, pág. 59 a 64.

BESSA, Valéria da Hora. Teorias da aprendizagem. Curitiba: IESDE Brasil, 2008.

BRASIL. Estatuto da Primeira Infância - Lei da 13.257, de 8 de março de 2016. Ministério da Educação. Brasília, 2016.

BRASIL. Lei de diretrizes e bases da educação nacional - LDB 9.394/96. Edição atualizada até março de 2017. Disponível em: < http://www2.senado.leg.br/bdsf/bitstream/handle/id/529732/lei_de_diretrizes_e_bases_1ed.pdf?s equence $=1>$. Acesso em 13 mai. 2020.

CURY, Lucilene. Revisitando Morin: os novos desafios para os educadores. Comunicação \& Educação. Ano XVII, n. 1, jan/jun 2012, pág. 39-47. Disponível em: <http://www.revistas.usp.br/comueduc/article/view/44901/48531 >. Acesso em 13 abr. 2020.

EL PAÍS. Três semanas sem merenda escolar em São Paulo: "Já deixei de almoçar para alimentar meus filhos" Reportagem de Heloísa Mendonça. Disponível em $<$ https://www.msn.com/pt-br/noticias/brasil/tr\%C3\%AAs-semanas-sem-merenda-escolar-ems\%C3\%A3o-paulo-\%E2\%80\%9Cj\%C3\%A1-deixei-de-almo\%C3\%A7ar-para-alimentar-meusfilhos $\%$ E2\% $80 \% 9$ D/ar-

BB12krkS?li=AAggXC1\&ocid=mailsignout\&fbclid=IwAR3KogkmZz5kcyHXRqGt9j1sf5mZjG3Dxs QDAzc8s3up5dDRnuZ_kZaBvfk >. Acesso em 11 mai. 2020.

FREIRE, Paulo. Pedagogia da autonomia. Saberes necessários à prática educativa. São Paulo: Paz e Terra, 1996.

Revista de Ciências Humanas, Frederico Westphalen - RS, , v. 21, n.1, p. 98-111, jan./abr. 2020. Recebido em: 27/10/2020 Aceito em: 08/02/2021 
FREIRE, Paulo. Pedagogia do oprimido. 54ª edição. Rio de Janeiro: Paz e Terra, 2013.

GIZZI, Jane Salvador de Bueno; MENDONÇA, Ricardo Nunes de. A crise do trabalho e o Covid19: o futuro não é mais como era antigamente. IN: Pandemias e pandemônio no Brasil [livro eletrônico]. AUGUSTO, Cristiane Brandão; SANTOS, Rogerio Dultra dos (org.) llustrações de Ruddolfo Carcalho. 1a. ed. São Paulo: Tirant lo Blanch, 2020, pág. 229-243.

MORIN, Edgar. As certezas são uma ilusão. Fronteiras do pensamento. CNRS - Le Journal por Francis Lecompte - 09.04.2020. Disponível em: <https://www.fronteiras.com/entrevistas/edgarmorin-as-certezas-sao-uma-ilusao >. Acesso em 12 mai. 2020.

MORIN, Edgar. Os sete saberes necessários à educação do futuro. 2 ed. São Paulo: Editora Cortez; Brasília: UNESCO, 2011.

RODRIGUES, Walace. Vulnerabilidade Educacional na Educação Infantil: Um Problema de Políticas Públicas. Revista Porto das Letras. Vol. 05, № 01, 2019, pág. 75-84. Disponível em: $<$ https://sistemas.uft.edu.br/periodicos/index.php/portodasletras/article/view/5276/14836 Acesso em 11 de mai. 2020.

RICO, Santiago Alba; LIRIA, Carlos Fernández. El naufragio del hombre. Hondarribia, Espanha: Editorial Hiru, 2010.

SANTANA, Edson. Filosofar é preciso: as grandes indagações filosóficas e os enigmas da Humanidade. São Paulo: DPL Editora, 2007.

SANTOS, Benerval Pinheiro. A escola brasileira: um mecanismo de triagem social. IN: Educação popular em tempos de inclusão: pesquisa e intervenção. SANTOS, Benerval Pinheiro; NOVAIS, Gercina Santana; SILVA, Lázara Cristina da (org.). Uberlândia: EDUFU, 2011, pág. 291-315.

ZAIDAN, Junia de Mattos; GALVÃO, Ana Carolina. Covid-19 e os abutres do setor educacional: a superexploração da força de trabalho escancarada. IN: Pandemias e pandemônio no Brasil [livro eletrônico]. AUGUSTO, Cristiane Brandão; SANTOS, Rogerio Dultra dos (org.) Ilustrações de Ruddolfo Carcalho. 1a. ed. São Paulo: Tirant lo Blanch, 2020, pág. 261-278. 